\title{
A better stock pricing model: A systematic literature review
}

\begin{tabular}{|c|c|}
\hline \multicolumn{2}{|c|}{$\begin{array}{l}\text { Authors: } \\
\text { Nsama Musawa }^{1} \text { (D) } \\
\text { Sumbye Kapena }{ }^{2} \text { (D) } \\
\text { Chanda Shikaputo }^{3} \text { (D) }\end{array}$} \\
\hline \multicolumn{2}{|c|}{$\begin{array}{l}\text { Affiliations: } \\
{ }^{1} \text { Department of Business } \\
\text { Studies, Mulungushi } \\
\text { University, Kabwe, Zambia }\end{array}$} \\
\hline \multicolumn{2}{|c|}{$\begin{array}{l}{ }^{2} \text { Department of Economics, } \\
\text { Copperbelt University, } \\
\text { Kitwe, Zambia }\end{array}$} \\
\hline \multicolumn{2}{|c|}{$\begin{array}{l}{ }^{3} \text { Department of Accounting } \\
\text { and Finance, Copperbelt } \\
\text { University, Kitwe, Zambia }\end{array}$} \\
\hline \multicolumn{2}{|c|}{$\begin{array}{l}\text { Corresponding author: } \\
\text { Nsama Musawa, } \\
\text { nsama.musawa@yahoo.com }\end{array}$} \\
\hline \multicolumn{2}{|c|}{$\begin{array}{l}\text { Dates: } \\
\text { Received: } 30 \text { Mar. } 2019 \\
\text { Accepted: } 24 \text { Jan. } 2020 \\
\text { Published: } 01 \text { Apr. } 2020\end{array}$} \\
\hline \multicolumn{2}{|c|}{$\begin{array}{l}\text { How to cite this article: } \\
\text { Musawa, N., Kapena, S. \& } \\
\text { Shikaputo, C., 2020, 'A better } \\
\text { stock pricing model: A } \\
\text { systematic literature review', } \\
\text { Journal of Economic and } \\
\text { Financial Sciences 13(1), } \\
\text { a472. https://doi.org/ } \\
\text { 10.4102/jef.v13i1.472 }\end{array}$} \\
\hline \multicolumn{2}{|c|}{$\begin{array}{l}\text { Copyright: } \\
\text { (C) 2020. The Authors. } \\
\text { Licensee: AOSIS. This work } \\
\text { is licensed under the } \\
\text { Creative Commons } \\
\text { Attribution License. }\end{array}$} \\
\hline \multicolumn{2}{|c|}{ Read online: } \\
\hline 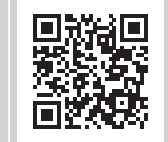 & $\begin{array}{l}\text { Scan this QR } \\
\text { code with your } \\
\text { smart phone or } \\
\text { mobile device } \\
\text { to read online. }\end{array}$ \\
\hline
\end{tabular}

Background: The Fama and French five-factor model (FF5M) is one of the stock valuation model that is on the cutting edge of finance research. Results from the empirical tests from various stock markets were the FFM5 has been tested since its launch in 2014 are mixed. Hence, it is important that empirical evidence testing the FF5M in comparison with lower models such as the Fama and French three-factor model (FF3M) and the Capital Asset Pricing Model $(\mathrm{CAPM})$ is documented.

Aim: To identify a research gap that still remains to be filled relating to stock valuation models in the field of finance.

Conclusion: The results of the empirical evidence have revealed that although the FF5M is a great milestone in stock pricing models, it has also left room for better models to be further developed from it in future.

Keywords: stock pricing model; Fama and French five-factor model; Fama and French three-factor model; Capital Asset Pricing Model (CAPM); systematic literature review.

\section{Introduction}

Stock valuation models are very important to investors and shareholders as they are one of the tools that enable them value their own shares so that they can make decisions on stock trading. Various stock valuation models have been developed to deal with stock valuation. Foremost is the modern portfolio theory by Markowitz (1952) who proposed that investors should focus on selecting portfolios based on their overall risk-reward characteristics instead of merely compiling portfolios of securities that individually had attractive risk-reward characteristics. The major weakness of the Markowitz portfolio theory was that it required large data inputs to find the variance and covariance of returns on security in the portfolio (Sharpe 1964). This led to the development of the Capital Asset Pricing Model (CAPM) by Sharpe (1964), Lintner (1965) and Mossin (1966). The CAPM builds on the model of portfolio selection developed by Harry Markowitz; it is considered one of the fundamental contributions to the exercise of finance, and it has long been a guide for academics and practitioners on how to find the relationship between average returns and risk. The CAPM postulates that the market portfolio is mean-variance efficient in the sense of Markowitz, and the model simply assumes that the equilibrium rates of return on all risky assets (or portfolios) are a linear function of their covariance with the market proxy. After more than 30 years of intense econometric investigation, several forms of the CAPM were developed on relaxed model realistic assumptions. The foremost among them was the Fama and French three-factor model (FF3M) (Fama \& French 1992, 1993). The FF3M extended the basic CAPM to include size and book-to-market as explanatory factors in explaining the cross-section of stock returns. After empirical tests, the FF3M could not explain the momentum effect presented by Jegadeesh and Titman (1993). This led to the formation of the four-factor asset pricing model developed by Carhart (1997). However, the latest studies like Fama and French (2015) have proved the four-factor model to be inadequate in explaining stock pricing and returns. Recently, Fama and French (2015) documented a five-factor model that is the modification of the FF3M. Although the FF3M includes the factors related to the market, the size of the firm and bookto-market, the Fama and French five-factor model (FF5M) adds profitability and investment. Fama and French state that the FF5M directed at capturing the size, value, profitability and investment patterns in average stock returns performs better than the FF3M. Since its launch in 2014, the FF5M has been empirically tested in various stock markets. Researchers have acknowledged that the FF5M is one of the newest methods among various methods for financial asset pricing and prediction of stock return, which has proved to be an enormous improvement compared with previous models. However, it has also left room for better models to be further developed from it in future (Anvary Rostamy 2017). The empirical results testing the FF5M are mixed; some are in 
support of the model whereas others are not, and others have suggested further improvement to it. This article therefore documents some empirical research that has been carried out to test the FF5M in comparison with the FF3M and the CAPM; it has highlighted the research gap and shown that the search for a better stock pricing model is still on.

\section{Methods}

An archival research design was used and the framework outlined by Schirmer (2018) for conducting and writing a systematic literature review was followed. The first step was selecting the research and theoretical literature; this involved developing a plan for which databases and other sources were used to obtain the most representative, comprehensive or exhaustive set of data for understanding the state of knowledge about the FF5M. Among the databases that were searched were ScienceDirect and Google Scholar. The first search showed 14 articles. After these were scrutinised, five articles that gave a detailed comparison of the FF5M, FF3M and the CAPM were selected for further analysis. Having more studies for review would have been better, but considering that the FF5M is the latest model not many studies comparing it with the lower models have been conducted. The second step was analysing each of the studies selected; this involved looking at the rationale, methodology, analysis, results, conclusions and interpretation. The third step was to identify the patterns and trends in the literature; this involved a critical analysis, description of gaps and inconsistencies and identification of methodological limitations in the body of research. The fourth and last step was writing the literature review narrative.

\section{Synthetic review of empirical findings comparing the Fama and French five-factor model with the Fama and French three-factor model and the Capital Asset Pricing Model}

This section presents an overview of the articles that were reviewed. It is presented as follows; for each article reviewed, the objectives, methodology and results are presented in one paragraph. Then there is another paragraph after each study that gives a critical analysis, describing gaps and inconsistencies and identification of methodological limitations. The section following this, gives an overall synthesis of key findings across the studies.

A number of researchers have tested the five-factor model in comparison with the three-factor model and the CAPM in different stock markets. The results are mixed, most of which have supported its superiority in explaining stock return variations compared to other models. For example, Singh and Yadav (2015) performed a study on the Indian stock market which is from an emerging economy in Asia. They justified the need for the study after considering past research, which had shown that the FF3M could not fully explain the return variations related to profitability and investment. The introduction of the new FF5M that had added profitability and investment to the three-factor model necessitated the need to test this new FF5M in India. Hence, the objective of this article was to test the applicability of the FF5M in the Indian stock market and compare its performance with the CAPM and the FF3M. The sample of the study was based on the constituent companies of CNX 500 Index covering the time period of 15 years, from October 1999 to September 2014. The data for the companies and the stock market were taken from the financial database - ACE Equity. The data on treasury bills were taken from the Reserve Bank of India website. In their methodology, they closely followed Fama and French $(1993,2015)$ methodology for defining and computing the variables. However, the following interventions were made. Firstly the companies for which all the four variables could be computed formed part of the study. Secondly, the companies with negative book values were not considered for the study. Further, they provided for the 6-month time gap whose justification was that the firms had a time span of 6 months after the end of accounting year to publish their accounting data. They reasoned that creating a portfolio without providing for this time gap would have meant that the results would be affected by look-ahead bias. This is the bias that arises when the studies include past period and use the data that would not have been available when the study intended to use it. In its data analysis, the article employed time series hierarchical multiple regression. The hierarchical regression was run in three steps. Step 1 ran the one factor CAPM; step 2 ran the FF3M, and step 3 ran the FF5M. To test if a more parsimonious model could be created, they re-ran the regression analysis using four-factor models, by dropping profitability and investment factors one at a time. Regression intercepts and adjusted $R$ Squired were compared for the three models. The results were that FF3M performed better than the CAPM for every portfolio, and the FF5M performed better than FF5M when the underlying portfolios were based on profitability and investment. The four-factor model without an investment factor had the highest explanatory power when the portfolio was not based on investment. For portfolios based on investment sorts, the FF5M had the highest explanatory power. Hence, the researchers concluded that for Indian data, except for cases in which portfolios are formed on investment, the four-factor model (without an investment factor) is a more parsimonious model.

From the above study by Singh and Yadav (2015), it can be observed that they closely followed the FF5M methodology. However, they used regression intercepts and the adjusted $R$ Squired in their analysis instead of the Gibbons, Ross and Shanken's (GRS) F-test statistics that were used by Fama and French. On a positive note, they went a step further and re-ran the regression analysis by using four-factor models, by dropping profitability and investment one at a time, and found that the four-factor model (without an investment factor) is a more parsimonious model for the Indian stock market data. 
In another similar study, Erdinç (2017) made the comparison of CAPM, FF3M and FF5M on the Turkish stock market. The reason for conducting this study arose from the wake of the findings of Fama and French who expanded the FF3M with profitability and investment. He argued that the FF5M was tested by using international data, but no such a study was performed by using the Turkish stock market data. So this study added to research conducted on the CAPM, FF3M and the new FF5M by testing all these models on the Turkish stock market. In the justification for the study, the author stressed that the study extended the asset pricing tests in three ways; firstly, it was the first application of the FF5M for the Turkish stock market. Secondly, it expanded the test of the FF3M to the Turkish market for a longer period; and thirdly, this was the first study that covered 17 years of the Turkish data. The data sample used in the analysis consisted of monthly price, total return and accounting data downloaded from 'Finnet Data Yayıncılık'. The data set contained 263 non-financial firms listed in BIST (Borsa Istanbul or Istanbul stock exchange) for the period between 1999 and 2017. Data were collected for all available active and dead stocks in Istanbul stock exchange totalling 204 observations. The 5-month gap between ends of the fiscal year and the portfolio formation was used as all the accounting data in BIST are available by the end of May of each year. The study used equal-weighted returns instead of value-weighted returns. The following interventions were performed in the study; at the end of each year, firms that had the following specifics were eliminated: (1) negative book-tomarket values were removed, and (2) the companies with yearly increase in their investment, which was either less than $50 \%$ or higher than $100 \%$ in a certain year, were eliminated as this would imply that the company in question lost half of its assets, or more than doubled its assets in the given year, which seemed very unlikely during normal recurring circumstances. Factor spanning regressions were used to test the explanatory power of the factors and the GRS test was used to find out if a model completely captured the sample return variation. After testing all the models (CAPM, FF3M and FF5M) with 48 different market portfolios, it was found that FF5M explained the common variation and the cross section of stock returns better than the FF3M and the CAPM. However, the GRS test on the joint set of all tested portfolios clearly rejected all tested models as complete descriptions of average returns. The CAPM model elicited the lowest average absolute alpha values of the three tested models throughout all tests but showed a statistically insignificant GRS value compared with other models.

Although this study by Erdinç (2017) followed the Fama and French methodology, a critique review of the study shows that unlike Fama and French who used 6-month gap between the ends of the fiscal year and the portfolio formation date, the study used the 5-month gap as all the accounting data in BIST are available by the end of May of each year. Additionally, although Fama and French used valueweighted returns in their study, Erdinç (2017) used equal-weighted returns. However, it is worth noting that despite using the equal-weighted returns, the results are still similar to those by Fama and French.

Huang (2019) carried out a study from the Shangahai Stock Exchange and the Shenzhen Stock Exchange in China as an emerging economy in Asia. In his rational for the study, he stated that past studies failed to consider some Chinese market features that might influence the model performance. He gave an example that Chinese shares could be traded on either the Shanghai Stock Exchange or the Shenzhen Stock Exchange. He argued that the stock exchange where stocks were sold probably affected the explanatory power of asset pricing models because of different market mechanisms. Further, rapid changes in the Chinese stock exchange since its foundation were also a factor that needed to be considered; he cited events like share structure reform that could have caused structural breaks in the Chinese stock market. With the mentioned anomalies, he wondered whether the common asset pricing factors provided consistent predictions for stock returns or these varied with time. Hence the purpose of the study was to explore the explanatory power of the FF5M for stock returns in China compared with other models and whether the pricing factors were robust or sensitive to market mechanisms and share-structure reforms. The study considered the sample that contained all available A-share stocks over the period of 1994-2016. Included were all Shanghai and Shenzhen Main Broad, Shenzhen Small and Medium-Sized Enterprise Board and Growth Enterprise Market stocks. Monthly returns series were used to measure stock returns and factor portfolio returns. While data on profitabilty and investment factors from financial statements were based on annual frequencies. The data were obtained from the Chinese stock market and Accounting Research database. In the methodology for the study regression was applied in two ways; the first was to the full sample of all excess returns and the second was on each firm. Further, the study considered some market features in China and examined whether the models' performance differed under the features such as capitalisation and ownership of the firm. The study compared the Shenzhen Stock Exchange and the Shanghai Stock Exchange. The study reviewed that the differences which might affect the results for two markets were capitalisation of the Shanghai Stock Exchange, which was higher than the Shenzhen Stock Exchange; further, firms on the Shanghai Stock Exchange were mainly state owned, whereas firms on the Shenzhen Stock Exchange engaged in manufacturing and exporting, and these firms tend to possess closer connection with foreign and institutional investors resulting in different degree of information asymmetry. The results showed that both size and value effects were stronger on the Shenzhen Stock Exchange than on the Shanghai Stock Exchange. The difference they said might have been caused by potential influence of market microstructure. It was found that implementation of share structure reforms was found to cause a structural change in the model performance. The study also performed a subperiod analysis; this is where the stability of the model performance was examined across years. This was important 
to see whether the model performance was a function of the number of observations or a specific time period. Hence, similar regression analysis was repeated year by year. The results for this sub-period analysis revealed that the explanatory power of the FF5M varied with time. Using the adjusted $R$ squared to compare the models' performance, the results for the study showed that the FF5M performed better than the FF3M and the CAPM.

A critique review of the study by Huang (2018) has reviewed that unlike the FF5M where portfolio returns were formulated and used as a dependant variable, the study used individual stock returns instead of portfolio returns as a dependant variable. The justification for not using portfolios was that past studies found that portfolio grouping significantly affected the results. Furthermore, unlike the FF5M where models were tested for each individual portfolio, this study used the whole sample of individual firms. Additionally, the study used expected returns on the monthly basis while factors were annually. Monthly returns series were used to measure stock returns and factor portfolio returns for financial statement were based on annual frequencies. Despite this, it is worth noting that the study has provided important additional details relating to the methodology of model testing, and the sub-period analysis has revealed that the explanatory power of the FF5M varies with time meaning that model performance differs with sample selection. This finding is very important as it implies that the sample period used in the study may influence the results.

Another interesting study from stock markets across the regions of Europe, Asia Pacific, North America, Japan and the USA, including Global and Global excluding the USA, was performed by Roy and Shijin (2019). In their motivation for the study, they acknowledged that the evidence showed that FF3M and FF5M predominantly captured the variation in return predictability. They explained that contemporary literature on capital asset pricing documented a series of diverse anomalies that contributed towards return predictability. However they argued that there was no study that tested the five variant empirical asset pricing models on international stock returns across Europe, Asia Pacific, North America, Japan and the USA, including Global and Global excluding the USA. Hence the study examined international stock returns with three objectives. First was to summarise the value, momentum, profitability and investment patterns in average returns across the seven regions. Second, they examined the country-specific asset pricing models in which the explanatory factors and the portfolio returns to be explained were from the identical region. Third, from the perspective of integration they tested whether the asset pricing was integrated across the regions. They further tested the models that used global factors to explain the global and regional portfolio returns. In the methodology, stock market across the regions, Europe, Asia Pacific, North America, Japan and the USA, were grouped in to four regions: Global, Europe, Asia Pacific and North America. Included in Global were Australia, Austria, Belgium, Canada, Switzerland, Germany, Denmark, Spain, Finland, France, Great Britain, Greece, Hong Kong, Ireland, Italy, Japan, the Netherlands, Norway, New Zealand, Portugal, Sweden, Singapore and the USA. Three hundred and twenty-four observations were obtained from the monthly data which ranged from 1991 to 2017. Europe included Austria, Belgium, Switzerland, Germany, Denmark, Spain, Finland, France, Great Britain, Greece, Ireland, Italy, the Netherlands, Norway, Portugal and Sweden with the same data range frequency and observations. Asia Pacific (excluding Japan) included, Australia, Hong Kong, New Zealand and Singapore with the same data range observations and frequency. North America included Canada and the USA. The source of data was French (2017) database. They assessed the average returns of portfolios formed on size-B/M, size-momentum, size-profitability and size-investment to capture the patterns employing the variant local and global versions of models, CAPM, FF3M, Carhart four-factor model and FF5M. Data analysis was performed using time-series regression. The judgement on the performance of the models was based on the models' explanatory power, the magnitude of model pricing errors and the GRS F-test statistics. The results were that while examining the international stock returns, they found value premiums in average returns in Europe, Asia Pacific, North America, Japan, the USA, Global and Global excluding the USA. There were strong momentum returns, and profitability and investment patterns in average returns in all the regions except for Japan. The international value, momentum and profitability premiums varied with firm size and premiums decreased from smaller to bigger stocks during the tests of the global models on four sets of variant global portfolio returns. The GRS test rejected all the global version models. Hence, the integrated pricing approach was rejected. In terms of model performance, the country-specific FF5M performed relatively better than the variant models in approximating the returns on Asia Pacific, North American and Japanese size-profitability portfolios. Similarly, the FF5M performed relatively better than the variant models in approximating the returns on European and Japanese size-investment portfolios.

This study by Roy and Shijin (2019) is unique in that it broadly examined the patterns in average returns on portfolios of different sorts covering all the developed markets in an asset pricing framework. It contributes to the literature on integrated global pricing.

From the small developing Lusaka Stock Exchange are studies by Musawa et al. (2018a, 2018b). In their rational for the study, they explained that capital markets play important roles in the economies of both developed and developing countries. They acknowledge that a number of models for dealing with capital markets have been developed, but on the cutting edge of these models was the FF5M that is at the centre of both academic and policy debate and was being empirically tested. The study was motivated by the fact that 
most of the studies testing the FF5M had been performed from the developed stock markets and few from the developing stock markets. The study filled part of this gap by testing the five-factor model at the developing stock market from Africa. The main objective of this study was to test how the latest FF5M fitted the data from the Zambian capital market compared with the way the FF3M and the CAPM fitted the same data. The data for the study ranged from 2008 to 2014. The market and financial data were gathered from the Lusaka Stock Exchange, and the treasury bills rates were collected from the Bank of Zambia. The study closely followed the Fama and French methodology and used regression analysis to test the suitability of the FF5M relative to the FF3M and CAPM. Regression was applied in two ways: the first was to the full sample of all excess returns and the second was on each portfolio excess returns. The results of the models' performance which were based on the adjusted $R$-squared test indicated that the FF5M was better than the FF3M and the CAPM. In all three models, absolute intercepts were not equal to zero. This indicated that all the three models, the FF5M, FF3M and CAPM, did not completely explain the variation in excess return in the Zambian case.

The study is unique in that it is among the first studies to test the FF5M from Africa. The study used regression intercept, although it did not employ the GRS statistics as used by Fama and French. The limitation of the study related to study period which is short compared with other studies testing the FF5M. However, it was important to carry out the study so as to have empirical evidence from a developing stock market.

\section{Synthesis of key findings across the studies}

From the above studies, it can be observed that in most studies from developed stock markets where the FF5M has been tested, the model has proved its superiority compared with the FF3M and the CAPM. However some studies like that by Singh and Yadav (2015) have suggested that a four-factor model is better than the FF5M. Further, although the FF5M is a great milestone to stock pricing literature, all of the studies reviewed have found that the FF5M does not fully explain all the variations in stock returns. This means that the search for a better stock pricing model is till on. Except for the studies by Musawa et al. (2018a, 2018b) from Zambia, most studies testing the FF5M have been performed in Europe and Asia; hence, this review has highlighted the need for more studies to be conducted in developing stock markets in Africa.

From a methodological point of view, the sub-period analysis by Huang (2018) has revealed that the explanatory power of the FF5M varies with time meaning that the stock model performance differs with sample selection. This revelation is very important as it implies that the sample period used in the study may influence the results. However, this result cannot be conclusive; there is a need for more studies to be performed from other stock markets so as to validate this finding. In addition, although Fama and French used portfolio-expected returns as a dependent variable, similar results in support of the superiority of the FF5M were found by Huang (2018) who used individual stock returns instead of portfolios. This may imply that either portfolio returns or stock returns can be used as a dependant variable in testing the FF5M. However this too cannot be conclusive; there is a need for more studies to be performed from other stock markets. In judging the model performance, some studies have employed GRS statistics, and others have used adjusted $R$ squared, but all of them have proved the superiority of the FF5M regardless of the method used to analyse the data.

\section{Implications and recommendations}

This article has revealed that although the FF5M is a great milestone in stock pricing models, the search for a better pricing model still continues. This implies that there is still a gap in finance literature relating to stock pricing models that needs to be filed up by researchers. The following are the recommendations: (1) Further research to test the five-factor model to be conducted in developing and developed markets, especially in African stock markets where little has been done. (2) From a methodological point of view, it has been revealed that the explanatory power of the FF5M varies with time meaning that the stock model performance differs with sample period. This implies that the sample period used in the study may influence the results. However, this result cannot be conclusive; there is a need for more studies to be performed from other stock markets so as to validate this finding. (3) Although Fama and French used portfolio-expected returns as a dependant variable, similar results have been found by studies that have used individual stock returns instead of portfolios. This may imply that either portfolio returns or stock returns can be used as a dependant variable in testing the FF5M. However this too cannot be conclusive; there is a need for more studies to be performed from other stock markets. (4) Some studies have suggested a modification to the FF5M. There is a need to test these modified models especially in stock markets where the FF5M has proved to be superior.

\section{Conclusion}

Although the FF5M is a great milestone, the empirical evidence documented in this article shows that the search for a better pricing model still continues. Given the divergence of results, there is a need to cover this knowledge gap by conducting more similar research in other stock markets.

\section{Acknowledgements}

The authors express their gratitude to Mulungushi University for paying the publication fees for this article.

\section{Competing interests}

The authors have declared that no competing interests exist. 


\section{Authors' contributions}

The lead author is N.M. All authors equally contributed to the research and writing of this article.

\section{Ethical considerations}

This article followed all ethical standards for a research without direct contact with human or animal subjects.

\section{Funding information}

This research was funded by the authors.

\section{Data availability statement}

Data sharing is not applicable to this article as no new data were created or analysed in this study.

\section{Disclaimer}

The views and opinions expressed in the article are those of the authors and not an official position of the institution or funder.

\section{References}

Anvary Rostamy, A.A., Rowshandel, S.R., Noravesh, I. \& Darabi, R., 2017, 'Examination of the predictive power of Fama-French five-factor model by the inclusion of skewness coefficient: Evidence of Iranian stock market', International Journal of Finance \& Managerial Accounting 2(6), 71-78.

Carhart, M., 1997, 'On persistence of persistence in mutual fund performance', Journal of Finance, 52, 57-82.
Erdinç, Y., 2017, 'Comparison of CAPM, three-factor Fama-French model and fivefactor Fama-French model for the Turkish stock market', in Financial management from an Emerging Market Perspective, pp. 69-92.

Fama, E.F. \& French, K.R., 1992, 'The cross-section of expected stock returns', The Journal of Finance 47(2), 427-465. https://doi.org/10.1111/j.1540-6261.1992. tb04398.x

Fama, E.F. \& French, K.R., 1993, 'Common risk factors in the returns on stocks and bonds', Journal of Financial Economics 33(1), 3-56. https://doi.org/10.1016/0304405X(93)90023-5

Fama, E.F. \& French, K.R., 2015, 'A five-factor asset pricing model', Journal of Financial Economics 116(1), 1-22. https://doi.org/10.1016/j.jfineco.2014.10.010

Huang, T.L., 2019, 'Is the Fama and French five-factor model robust in the Chinese stock market?', Asia Pacific Management Review, 24(3), 278-289.

Jegadeesh, N. \& Titman, S., 1993, 'Returns to buying winners and selling losers: Implications for stock market efficiency', The Journal of Finance 48(1), 65-91. https://doi.org/10.1111/j.1540-6261.1993.tb04702.x

Lintner, J., 1965, 'Security prices, risk, and maximal gains from diversification', The Journal of Finance 20(4), 587-615. https://doi.org/10.1111/j.1540-6261.1965. tb02930.x

Markowitz, H., 1952, 'Portfolio selection', The Journal of Finance 7(1), 77-91. https:// doi.org/10.1111/j.1540-6261.1952.tb01525.x

Mossin, J., 1966, 'Equilibrium in a capital asset market', Econometrica: Journal of the Econometric Society 34(4), 768-783. https://doi.org/10.2307/1910098

Musawa, N., Kapena, S. \& Shikaputo, C., 2018a, 'A comparative analysis of FamaFrench Five and Three-Factor model in explaining stock returns variation', International Journal of Economics 3(1), 30-48.

Musawa, N., Kapena, S. \& Shikaputo, C., 2018b, 'A test of the Fama-French five factor model in comparison to the capital asset pricing model at the Lusaka Securities Exchange', International Journal of Finance and Accounting 3(1), 35-47.

Roy, R. \& Shijin, S., 2019, 'The nexus of anomalies-stock returns-asset pricing models: The international evidence', Borsa Istanbul Review 19(1), 1-14. https://doi. org/10.1016/j.bir.2018.07.003

Schirmer, B.R., 2018, 'Framework for conducting and writing a synthetic', International Journal of Education 10(1), 94-105. https://doi.org/10.5296/ije. v10i1.12799

Sharpe, W.F., 1964, 'Capital asset prices: A theory of market equilibrium under conditions of risk', The Journal of Finance 19(3), 425-442. https://doi. org/10.1111/j.1540-6261.1964.tb02865.x

Singh, S. \& Yadav, S.S., 2015, 'Indian stock market and the asset pricing models', Procedia Economics and Finance 30, 294-304. https://doi.org/10.1016/S2212 5671(15)01297-6 